\title{
Dynamic Instability of High-Speed Rotating Shaft with Torsional Effect
}

\author{
A. M. A. Wahab ${ }^{1}$, Z. Yusof ${ }^{2}$, Z. A. Rasid $^{2 *}$, A. Abu ${ }^{2}$ and N. F. M. N. Rudin ${ }^{2}$ \\ ${ }^{1}$ Faculty of Mechanical Engineering, Universiti Teknologi MARA \\ 40450 Shah Alam, Selangor, Malaysia \\ ${ }^{2}$ Malaysia-Japan International Institute of Technology, \\ Universiti Teknologi Malaysia Kuala Lumpur, 54100 Kuala Lumpur, Malaysia \\ *Email: arzainudin.kl@utm.my \\ Phone: +6 03022031332
}

\begin{abstract}
Today's design of machine rotor requires the rotor to operate at a high rotational speed to improve the efficiency of the machine. However, the existence of disturbances such as periodic axial load may cause parametric resonance to the rotor system in addition to the common force resonance. Previous studies on this parametric resonance of shaft typically included the element of translational and rotary inertia, gyroscopic moments and bending and shear deformation but surprisingly neglected the effect of the axial torque. This paper investigated the parametric instability behaviour of the shaft rotating at high speed while considering the torsional effect of the shaft. Based on the finite element method, a shaft model that includes torsional deformation as one of its degree of freedom was established. The Mathieu-Hill equation was derived, and then the Bolotin's method was used to solve the equation by establishing the parametric instability chart. Two types of the rotary system were studied: a shaft with different boundary conditions and shaft with different bearing types. The results were initially validated with past findings. Following that the results were compared to the results correspond to the Timoshenko's beam formulation that omits the torsional degree of freedom. The effect of axial torsional deformation was found to be very significant especially at high speed. The developed model in this study shows that at the shaft speed of $40000 \mathrm{rpm}$, the effect of torsional deformation has given the difference of more than $100 \%$ in the frequency ratios correspond to the 4DOF and 5DOF models for the case of fix-free boundary condition.
\end{abstract}

Keywords: Parametric instability; torsional effect; Mathieu-Hill equation; Bolotin's method; Strut-Ince diagram.

\section{INTRODUCTION}

Parametric resonance or parametric instability of shaft is an important type of dynamic failure that has been the subject of intensive research especially in the area of automotive, aerospace and mechanical engineering in general [1-4]. Compared to whirling resonance in shaft [5] that occurs when the natural frequency of the shaft is equal to the rotating speed, parametric resonance occurrence is due to modification of the system parameters such as inertia and stiffness in time-varying manner. The periodic modification of stiffness, for example, can be due to the existence of geometric asymmetry of shaft [6], anisotropic bearing support [7], crack propagation [8] and periodic axial compressive load [9]. As in the force resonance, parametric instability can cause catastrophic failure to the rotor system for a small parametric excitation. Chen and $\mathrm{Ku}[10]$ developed finite element 
formulation to identify parametric instability of simple rotating shaft while including the gyroscopic and transverse shear effect. Using the Bolotin's method, the regions of dynamic instability were found to be shifted out while the instability sizes were increased as the rotational speed of the shaft increased. Later, a similar effect of increasing instability with increasing speed was found by $\mathrm{Ku}$ and Chen [11] in their study on the parametric instability of Timoshenko shaft-disc system while considering the effects of translational and rotary inertia, gyroscopic moments and bending and shear deformation. On the other hand, using a different method by analysing the intersections between the operation line of the shaft and the branches of the Mathieu eigenvalues in the Mathieu map (a,q), Raffa and Vatta [12] successfully determined the instability chart analytically while assuming the shaft as the Euler-Bernoulli and Raleigh beams. a and $\mathrm{q}$ are nondimensionalised terms that group the $\mathrm{k}^{\text {th }}$ natural frequency, $\mathrm{k}^{\text {th }}$ critical load of the beam and respectively, the static and dynamic components of the axial load. Chen [13] however contradicts the above finding [10] and [11] and others [14-17] where using Floquet's method instead of the Bolotin's method, the finding was the obtained instability of a rotor system may not be increased as the rotational speed of the shaft is increased. In their research, Chen and Chen [9] studied the effects of locally distributed Kelvin-Voight damping on the parametric instability of Timoshenko beams. They found that the effect of damping especially the one that is located near to the fixed end of the beam is to make the beam more stable. The shear deformation was neglected as the transfer matrix method was applied by Yim and Yim [18] to show that disk location plays an important role on dynamic instability of a rotor-bearing system under axial load. The closer the location of the disk to the support, the more the decrease of critical axial force.

All of the mentioned studies, however, do not emphasize on the high-speed shaft systems. The rotating equipment that operates at high speed may cause the machine to have high overall efficiency [19]. Despite this, previous studies only concentrated on the effects of translational and rotary inertia, gyroscopic moment, damping, bending and shear deformations. Surprisingly, the important effect of torsional deformation has been left out. Nelson [19] and Rao [20] investigated the additional effect of the axial torque. However the focus was merely on the critical speed and the whirling frequency of the rotor system. Therefore, this paper reports on the behaviour of the dynamic instability of Timoshenko shaft system rotating at high speed considering the effect of the axial torque while it is subjected to periodic axial load. Finite element method (FEM) was used to develop the Mathieu-Hill equation while the study applied the commonly used method of Bolotin to give the instability chart. The results are validated and compared to the results correspond to a formulation that neglected the axial torque effect. The instability charts correspond to the effect of various boundary conditions, and two types of bearing are plotted.

\section{METHODS AND MATERIALS}

\section{Shaft System}

In this study, the shaft system comprises of a shaft with support such as shown in Figure 1. Based on this, two cases were considered in this study:

i. A simple shaft that applies rigid bearings at A and B of Figure 1 i.e. the shaft is pin supported at ends A and B and;

ii. a shaft supported by two kinds of bearings i.e. the anisotropic and isotropic bearings located at A and B of Figure 1. $\mathrm{P}(\mathrm{t})$ is the pulsating axial force such as 
$\mathrm{P}(\mathrm{t})=\mathrm{P}_{\mathrm{s}}+\mathrm{P}_{\mathrm{t}} \cos \phi \mathrm{t}$ where $\phi$ is the frequency of the axial excitation, $P_{s}$ and $P_{t}$ are the time independent and dependent components of the force respectively. While, $\Omega$ is the spin speed ranges from 0 to $40,000 \mathrm{rpm}$ that considered in this study.

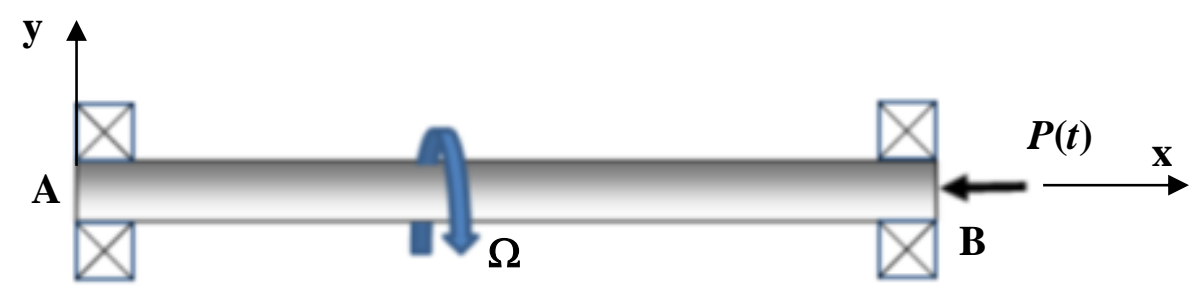

Figure 1. The rotor system understudy.

The linear isotropic bearing used in this work is due to a direct relationship between force, displacement and velocity while for anisotropic viscosity bearing, the model is based on a linearised solution of Reynold's equation. Figure 2 shows the shaft cross-section and the bearing model. The stiffness and damping properties of the bearing can be seen in the figure for the case of isotropic and anisotropic bearings. $\mathrm{C}_{\mathrm{by}}$ and $\mathrm{C}_{\mathrm{bz}}$ are the damping coefficients of the bearing in $y$ and z-axis respectively while $K_{b y}$ and $K_{b z}$ are the stiffness coefficients of the bearing in $\mathrm{y}$ and $\mathrm{z}$-axis respectively. The isotropic bearing is when $K_{b y}$ and $K_{b z}$ have the same value and when the two values are not the same, the bearing becomes anisotropic. The damping effect of the bearing is however neglected in this study. The stiffness of the isotropic bearing is considered to have three levels: soft, intermediate and stiff as specified in Table 1. The shaft has the Young's, shear modulus and Poisson's ratio of $207 \mathrm{GPa}, 79.6 \mathrm{GPa}$ and 0.303 respectively. The density is $7833 \mathrm{~kg} / \mathrm{m}^{3}$. The radius of the shaft is $0.508 \mathrm{~m}$ while the length is $1.27 \mathrm{~m}$.

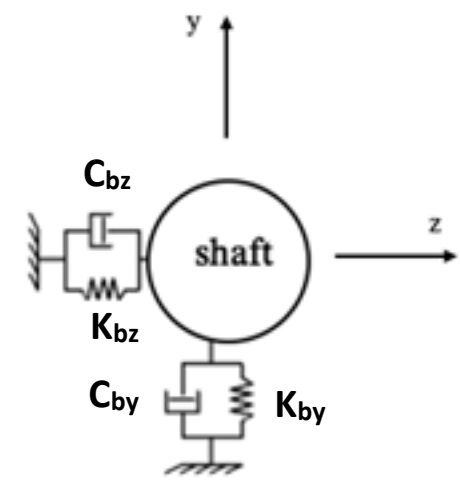

Figure 2. The bearing models.

\section{Finite Element Formulation}

This research employs FEM to estimate the parametric instability region of the stated high-speed rotor system while considering the torsional effect of the shaft. The FEM formulation that is developed here applies the five degree of freedom (DOF) per node element that was suggested by Nelson [21] and Rao [20] where the axial torsional deformation is included as one of the DOF. This FEM model is called the 5DOF model while the formulation that is developed based on the four DOF per node element that 
neglects the torsional deformation is called the 4DOF model. The parametric instability equation in the form of the Mathieu-Hill equation is developed based on the FEM formulation of the rotor. Furthermore, the Bolotin's method [22] is used to estimate the stable and unstable regions of the shaft concerning the parametric instability behaviour.

Table 1. The bearing properties of the components of the rotor system.

\begin{tabular}{|c|c|c|c|c|c|c|}
\hline \multirow[b]{2}{*}{ Bearing type } & \multicolumn{5}{|c|}{ Direct stiffness coefficient $(\mathrm{N} / \mathrm{m})$} & \multirow{2}{*}{$\begin{array}{c}\text { Direct } \\
\text { damping } \\
\text { coefficient } \\
\mathrm{C}_{\mathrm{by}}, \mathrm{C}_{\mathrm{bz}}\end{array}$} \\
\hline & $\mathrm{K}_{\mathrm{by}}, \mathrm{K}_{\mathrm{bz}}$ & $\mathrm{K}_{\text {by1 }}$ & $\mathrm{K}_{\mathrm{bz2}}$ & $\mathrm{K}_{\text {by } 1}$ & $\mathrm{~K}_{\mathrm{bz} 2}$ & \\
\hline Stiff isotropic & $2.49 \times 10^{7}$ & & & & & 0 \\
\hline $\begin{array}{l}\text { Intermediate } \\
\text { isotropic }\end{array}$ & $1.1 \times 10^{7}$ & & & & & 0 \\
\hline Soft isotropic & $4.5 \times 10^{5}$ & & & & & 0 \\
\hline Anisotropic & & $2.49 \times 10^{7}$ & $1.76 \times 10^{7}$ & $1.10 \times 10^{8}$ & $2.17 \times 10^{8}$ & 0 \\
\hline
\end{tabular}

\section{Stress-Strain Relationship}

Figure 3 shows the shaft element that is used to establish the 5DOF FEM formulation. The model involves two translation components in $\mathrm{y}$ and $\mathrm{z}$-direction $(\mathrm{v}, \mathrm{w})$ and three rotary inertia components $\left(\theta_{\mathrm{y}}, \theta_{\mathrm{z}}, \theta_{\mathrm{x}}\right)$ about $\mathrm{y}, \mathrm{z}$ and $\mathrm{x}$-axes respectively. Applying the commonly used stress, strain and deformation symbols, the strains subjected to the bending condition are given as;

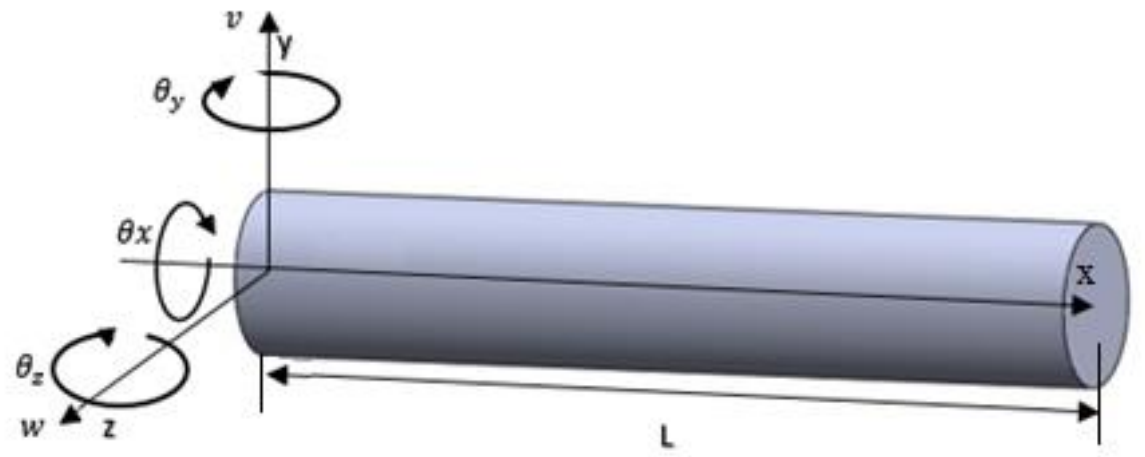

Figure 3. The torsional-bending element.

$$
\begin{aligned}
& \varepsilon_{\mathrm{y}_{\mathrm{b}}}=\frac{\partial \mathrm{v}}{\partial \mathrm{x}}=-\mathrm{y} \frac{\partial \theta_{\mathrm{z}}}{\partial \mathrm{x}}, \varepsilon_{\mathrm{z}_{\mathrm{b}}}=\frac{\partial \mathrm{w}}{\partial \mathrm{x}}=\mathrm{z} \frac{\partial \theta_{\mathrm{y}}}{\partial \mathrm{x}}, \varepsilon_{\mathrm{x}_{\mathrm{b}}}=\frac{\partial \mathrm{u}}{\partial \mathrm{x}}=0 \\
& \varepsilon_{\mathrm{xz}_{\mathrm{b}}}=\frac{\partial \mathrm{u}}{\partial \mathrm{z}}+\frac{\partial \mathrm{w}}{\partial \mathrm{x}}=\theta_{\mathrm{y}}(\mathrm{x})+\frac{\partial \mathrm{w}(\mathrm{x})}{\partial \mathrm{x}}, \varepsilon_{\mathrm{xy}_{\mathrm{b}}}=\frac{\partial \mathrm{u}}{\partial \mathrm{y}}+\frac{\partial \mathrm{v}}{\partial \mathrm{x}}=-\theta_{\mathrm{z}}(\mathrm{x})+\frac{\partial \mathrm{v}(\mathrm{x})}{\partial \mathrm{x}} \\
& \varepsilon_{\mathrm{xz}_{\mathrm{b}}}=\frac{\partial \mathrm{u}}{\partial \mathrm{z}}+\frac{\partial \mathrm{w}}{\partial \mathrm{x}}=\theta_{\mathrm{y}}(\mathrm{x})+\frac{\partial \mathrm{w}(\mathrm{x})}{\partial \mathrm{x}}, \varepsilon_{\mathrm{xx}_{\mathrm{b}}}=\varepsilon_{\mathrm{yy}_{\mathrm{B}}}=\varepsilon_{\mathrm{zz}_{\mathrm{B}}}=\varepsilon_{\mathrm{yz}_{\mathrm{B}}}=0
\end{aligned}
$$

While the stresses subjected to the bending condition are as in Eq. (2). 


$$
\begin{aligned}
& \sigma_{y_{b}}=E \frac{\partial v}{\partial x}=E\left(-y \frac{\partial \theta_{z}}{\partial x}\right), \sigma_{z b}=E \frac{\partial w}{\partial x}=E\left(z \frac{\partial \theta_{y}}{\partial x}\right) \\
& \sigma_{x_{b}}=\kappa G \varepsilon_{x y}=\kappa G\left(-\theta_{z}(x)+\frac{\partial v(x)}{\partial x}\right), \sigma_{x z b}=\kappa G \varepsilon_{x z}=\kappa G\left(\theta_{y}(x)+\frac{\partial w(x)}{\partial x}\right) \\
& \sigma_{x_{x}}=\sigma_{y_{y}}=\sigma_{z_{z}}=\sigma_{y_{z}}=\sigma_{x_{b}}=0
\end{aligned}
$$

Where $\kappa$ is the shear correction factor. In torsional condition, strains are express as Eq. (3).

$$
\begin{aligned}
& \varepsilon_{\mathrm{y}_{\mathrm{t}}}=\varepsilon_{\mathrm{z}_{\mathrm{t}}}=\varepsilon_{\mathrm{yy}_{\mathrm{t}}}=\varepsilon_{\mathrm{zz}_{\mathrm{t}}}=\varepsilon_{\mathrm{yz}}=0 \\
& \varepsilon_{\mathrm{x}_{\mathrm{t}}}=\frac{\partial^{2} \theta_{\mathrm{x}}}{\partial \mathrm{x}^{2}} \psi, \varepsilon_{\mathrm{xy}}=\frac{\partial \mathrm{u}}{\partial \mathrm{y}}+\frac{\partial \mathrm{v}}{\partial \mathrm{x}}=\frac{\partial \theta_{\mathrm{x}}}{\partial \mathrm{x}}\left(\frac{\partial \psi}{\partial \mathrm{y}}-\mathrm{z}\right), \varepsilon_{\mathrm{xz}}=\frac{\partial \mathrm{u}}{\partial \mathrm{z}}+\frac{\partial \mathrm{w}}{\partial \mathrm{x}}=\frac{\partial \theta_{\mathrm{x}}}{\partial \mathrm{x}}\left(\frac{\partial \psi}{\partial \mathrm{y}}+\mathrm{y}\right)
\end{aligned}
$$

The stresses subjected to the torsional condition are in Eq. (4).

$$
\sigma_{x_{t}}=G\left(\frac{\partial \theta_{x}}{\partial x}\left(\frac{\partial \psi}{\partial y}-z\right)\right), \sigma_{x z_{t}}=G\left(\frac{\partial \theta_{x}}{\partial x}\left(\frac{\partial \psi}{\partial y}+y\right)\right), \sigma_{x_{x}}=\sigma_{y_{t}}=\sigma_{z_{t}}=\sigma_{x_{y z}}=0
$$

\section{Energy Equation}

The bending and torsional deformations result in the total strain energy, $U$ stored in the shaft such that;

$$
\begin{aligned}
& U=\frac{1}{2} \int_{-\mathrm{a}}^{+\mathrm{a}} \sigma_{\mathrm{y}_{\mathrm{b}}} \varepsilon_{\mathrm{y}_{\mathrm{b}}}+\sigma_{\mathrm{zb}_{\mathrm{b}}} \varepsilon_{\mathrm{z}_{\mathrm{b}}} \mathrm{dV}+\frac{1}{2} \int_{-\mathrm{a}}^{+\mathrm{a}} \sigma_{\mathrm{xy}_{\mathrm{b}}} \varepsilon_{\mathrm{xy}_{\mathrm{b}}}+\sigma_{\mathrm{xzb}_{\mathrm{b}}} \varepsilon_{\mathrm{xz}_{\mathrm{b}}} \mathrm{dV}+ \\
& \frac{1}{2} \int_{-\mathrm{a}}^{+\mathrm{a}} \sigma_{\mathrm{xy}_{\mathrm{t}}} \varepsilon_{\mathrm{xy}_{\mathrm{t}}}+\sigma_{\mathrm{xz}_{\mathrm{t}}} \varepsilon_{\mathrm{xz}_{\mathrm{t}}} \mathrm{dV}
\end{aligned}
$$

Substituting the stress and strain equations in (1) - (4) into Eq. (5) and adding the pulsating force term, we have Eq. (6).

$$
\begin{aligned}
& \mathrm{U}=\frac{1}{2} \int_{-\mathrm{a}}^{+\mathrm{a}} \mathrm{EI}_{\mathrm{p}}\left(\dot{\theta}_{\mathrm{z}}^{2}+\dot{\theta}_{\mathrm{y}}^{2}\right) \mathrm{dx}+\frac{1}{2} \int_{-\mathrm{a}}^{+\mathrm{a}} \kappa \mathrm{GA}\left(\dot{\mathrm{v}}^{-}-\theta_{\mathrm{z}}\right)^{2}+\kappa \mathrm{GA}\left(\hat{\mathrm{w}}^{\mathrm{w}}+\theta_{\mathrm{y}}\right)^{2} \mathrm{dx} \\
& +\frac{1}{2} \int_{-\mathrm{a}}^{+\mathrm{a}} \mathrm{GJ} \hat{\theta}_{\mathrm{x}}^{2} \mathrm{dx}-\frac{1}{2} \int_{-\mathrm{a}}^{+\mathrm{a}} \mathrm{P}\left[\left(\hat{v}^{2}\right)^{2}+\left(\dot{w}^{\prime}\right)^{2}\right] \mathrm{dx}
\end{aligned}
$$

where $\mathrm{I}_{\mathrm{y}}$ and $\mathrm{I}_{\mathrm{z}}$ are moment of inertia with respect to $y$-axis and $z$-axis respectively and $\mathrm{J}$ is the polar moments of inertia per unit length of shaft element. Furthermore $I_{p}$ is the total second moment of inertia of the shaft element, $\theta$ is the slope deflection in rotational 
direction and $\mathrm{v}$ is the slope deflection in vertical direction. The kinetic energy of beam element in term of bending and torsional condition is in Eq. (7).

$$
\begin{aligned}
& \mathrm{T}=\frac{1}{2} \int_{-\mathrm{a}}^{+\mathrm{a}} \rho \mathrm{A}\left(\left(\frac{\partial \mathrm{v}}{\partial \mathrm{t}}\right)^{2}+\left(\frac{\partial \mathrm{w}}{\partial \mathrm{t}}\right)^{2}\right) \mathrm{dx}+\frac{1}{2} \int_{-\mathrm{a}}^{+\mathrm{a}} \rho \mathrm{I}_{\mathrm{y}}\left(\frac{\partial \theta_{\mathrm{y}}}{\partial \mathrm{t}}\right)^{2}+\rho \mathrm{I}_{\mathrm{z}}\left(\frac{\partial \theta_{\mathrm{z}}}{\partial \mathrm{t}}\right)^{2} \mathrm{dx} \\
& +\frac{1}{2} \int_{-\mathrm{a}}^{+\mathrm{a}} \rho \mathrm{I}_{\mathrm{x}}\left(\frac{\partial \theta_{\mathrm{x}}}{\partial \mathrm{t}}\right)^{2} \mathrm{dx}
\end{aligned}
$$

The shaft is considered rotating at constant angular velocity $\Omega$ about the $x$-axis and small deformation is neglected. Applying the Euler angle transformation, the total kinetic energy is derived as Eq. (8).

$$
\begin{aligned}
& \mathrm{T}=\frac{1}{2} \int_{-\mathrm{a}}^{+\mathrm{a}} \rho \mathrm{A}\left((\dot{\mathrm{v}})^{2}+(\dot{\mathrm{w}})^{2}\right) \mathrm{dx}+\frac{1}{2} \int_{-\mathrm{a}}^{+\mathrm{a}} \rho \mathrm{I}_{\mathrm{y}}\left(\dot{\theta}_{\mathrm{y}}\right)^{2}+\rho \mathrm{I}_{\mathrm{z}}\left(\dot{\theta}_{\mathrm{z}}\right)^{2} \mathrm{dx} \\
& +\int_{-\mathrm{a}}^{+\mathrm{a}} \rho \mathrm{I}_{\mathrm{x}} \theta_{\mathrm{z}} \dot{\theta}_{\mathrm{y}} \mathrm{dx} \Omega+\frac{1}{2} \int_{-\mathrm{a}}^{+\mathrm{a}} \rho \mathrm{I}_{\mathrm{x}}\left(\dot{\theta}_{\mathrm{x}}\right)^{2} \mathrm{dx}
\end{aligned}
$$

\section{Finite Element Implementation}

In a standard FEM procedure, the discretisation of the shaft is conducted where elements with two nodes are used. Each node carries 5 degree of freedom for the 5DOF model. The elemental potential energy is

$$
\mathrm{U}^{(\mathrm{e})}=\frac{1}{2}\left\{\mathrm{q}^{(\mathrm{e})}\right\}^{\mathrm{T}}\left(\left[\mathrm{K}_{\mathrm{b}}^{(\mathrm{e})}\right]+\left[\mathrm{K}_{\mathrm{s}}^{(\mathrm{e})}\right]+\left[\mathrm{K}_{\mathrm{t}}^{(\mathrm{e})}\right]\right)\left\{\mathrm{q}^{(\mathrm{e})}\right\}-\frac{1}{2}\left\{\mathrm{q}^{(\mathrm{e})}\right\}^{\mathrm{T}} \mathrm{P}(\mathrm{t})\left[\mathrm{K}_{\mathrm{g}}^{(\mathrm{e})}\right]\left\{\mathrm{q}^{(\mathrm{e})}\right\}
$$

where $\left[\mathrm{K}_{\mathrm{b}}{ }^{(\mathrm{e})}\right],\left[\mathrm{K}_{\mathrm{s}}{ }^{(\mathrm{e})}\right],\left[\mathrm{K}_{\mathrm{t}}{ }^{(\mathrm{e})}\right]$ and $\left[\mathrm{K}_{\mathrm{g}}{ }^{(\mathrm{e})}\right]$ are the elemental bending, shear, torsional and geometric stiffness matrices. The elemental kinetic energy is

$$
\mathrm{T}^{(\mathrm{e})}=\frac{1}{2}\left\{\dot{\mathrm{q}}^{(\mathrm{e})}\right\}^{\mathrm{T}}\left(\left[\mathrm{M}_{\mathrm{d}}{ }^{(\mathrm{e})}\right]+\left[\mathrm{M}_{\mathrm{r}}{ }^{(\mathrm{e})}\right]+\left[\mathrm{M}_{\mathrm{t}}^{(\mathrm{e})}\right]\right)\left\{\dot{\mathrm{q}}^{(\mathrm{e})}\right\}+\frac{1}{2}\left\{\dot{\mathrm{q}}^{(\mathrm{e})}\right\}^{\mathrm{T}}\left[\mathrm{G}^{(\mathrm{e})}\right] \Omega\left\{\mathrm{q}{ }^{(\mathrm{e})}\right\}
$$

where the matrices $\left[\mathrm{M}_{\mathrm{d}}{ }^{(\mathrm{e})}\right],\left[\mathrm{M}_{\mathrm{r}}{ }^{(\mathrm{e})}\right]$ and $\left[\mathrm{M}_{\mathrm{t}}{ }^{(\mathrm{e})}\right]$ are the element translational, rotary inertia and torsional mass matrix respectively. The $\left[\mathrm{G}^{(\mathrm{e})}\right]$ is the gyroscopic element matrix of the rotor system. Upon assembly process of elemental matrices, the global $\mathrm{U}$ and $\mathrm{T}$ of rotating Timoshenko shaft subjected to axial loading are as shown in Eq. (11) and (12).

$$
\begin{aligned}
& \mathrm{U}=\frac{1}{2}\{\mathrm{q}\}^{\mathrm{T}}[\mathrm{K}]\{\mathrm{q}\}-\frac{1}{2}\{\mathrm{q}\}^{\mathrm{T}} \mathrm{P}(\mathrm{t})\left[\mathrm{K}_{\mathrm{g}}\right]\{\mathrm{q}\} \\
& \mathrm{T}=\frac{1}{2}\{\dot{\mathrm{q}}\}^{\mathrm{T}}[\mathrm{M}]\{\dot{\mathrm{q}}\}+\frac{1}{2}\{\dot{\mathrm{q}}\}^{\mathrm{T}} \Omega[\mathrm{G}]\{\mathrm{q}\}
\end{aligned}
$$


where the global matrices $[\mathrm{K}],[\mathrm{M}],[\mathrm{G}]$ and $\left[\mathrm{K}_{\mathrm{g}}\right]$ of the shaft, system correspond to the elastic, mass gyroscopic and geometric stiffness matrices respectively. Applying the Lagrange's equation, the governing equation is:

$$
[\mathrm{M}]\{\ddot{\mathrm{q}}\}+\Omega[\mathrm{G}]\{\dot{\mathrm{q}}\}+\left([\mathrm{K}]-\mathrm{P}(\mathrm{t})\left[\mathrm{K}_{\mathrm{g}}\right]\right)\{\mathrm{q}\}=0
$$

\section{Estimating Parametric Instability Region}

The periodic axial force is $\mathrm{P}(\mathrm{t})=\mathrm{P}_{\mathrm{s}}+\mathrm{P}_{\mathrm{t}}$. The Mathieu-Hill equation can be obtained if the static and dynamic component of force are denoted as a portion of the buckling load, $P_{\mathrm{cr}}$. As such, it can be written as $\mathrm{P}(\mathrm{t})=\alpha \mathrm{P}_{\mathrm{cr}}+\beta \mathrm{P}_{\mathrm{cr}} \cos \phi \mathrm{T}$, where the static and the dynamic load factors are denoted as $\alpha$ and $\beta$ respectively. Substituting this equation into Eq. (13), the Mathieu-Hill type of equation can be written as Eq. (14).

$$
[\mathrm{M}]\{\ddot{\mathrm{q}}\}+\Omega[\mathrm{G}]\{\dot{\mathrm{q}}\}+\left([\mathrm{K}]-\left[\mathrm{K}_{\mathrm{g}}\right]\left(\alpha \mathrm{P}^{*}+\beta \mathrm{P}^{*} \cos \phi \mathrm{T}(\mathrm{t})\right)\{\mathrm{q}\}=0\right.
$$

Using the Bolotin's method [22], through the first-order approximation of the primary stability boundaries with period $2 T$ and the term-wise comparison of the sine and cosine coefficients will give infinite systems of homogeneous algebraic equations such that the condition of solvability is an infinite eigenvalue problem which, can be estimated by simplified and finite one such as Eq. (15).

$$
\left|\begin{array}{cc}
{[\mathrm{K}]+\left(\alpha-\frac{\beta}{2}\right)\left[\mathrm{K}_{\mathrm{g}}\right]-\frac{\phi^{2}}{4}[\mathrm{M}]} & -\frac{\phi}{2} \Omega[\mathrm{G}] \\
\frac{\phi}{2} \Omega[\mathrm{G}] & {[\mathrm{K}]+\left(\alpha+\frac{\beta}{2}\right)\left[\mathrm{K}_{\mathrm{g}}\right]-\frac{\phi^{2}}{4}[\mathrm{M}]}
\end{array}\right|=0
$$

Equation (15) can be written as:

$$
\begin{gathered}
\|\left[\begin{array}{cc}
{[\mathrm{K}]+\left(\alpha-\frac{\beta}{2}\right)\left[\mathrm{K}_{\mathrm{g}}\right]} & 0 \\
0 & {[\mathrm{~K}]+\left(\alpha+\frac{\beta}{2}\right)\left[\mathrm{K}_{\mathrm{g}}\right]}
\end{array}\right]+\phi\left[\begin{array}{cc}
0 & -\frac{1}{2} \Omega[\mathrm{G}] \\
\frac{1}{2} \Omega[\mathrm{G}] & 0
\end{array}\right] \\
+\phi^{2}\left[\begin{array}{cc}
-\frac{1}{4}[\mathrm{M}] & 0 \\
0 & -\frac{1}{4}[\mathrm{M}]
\end{array}\right] \|=0
\end{gathered}
$$

The condition of solvability for Eq. (16) appears as quadratic eigenvalue problem such as Eq. (17). Utilising the linearization approach [23] to express Eq. (17) into an eigenvalue problem of the $2 n \times 2 n$ size, we have Eq. (18).

$$
\left(\phi^{2}\left[\mathrm{M}_{\mathrm{E}}\right]+\phi\left[\mathrm{G}_{\mathrm{E}}\right]+\left[\mathrm{K}_{\mathrm{E}}\right]\right) \mathrm{q}=0
$$

$(\mathrm{N}-\phi R) \mathrm{n}=0$ 
Where,

$$
\mathrm{n}=\left[\begin{array}{c}
\phi \mathrm{q} \\
\mathrm{q}
\end{array}\right] ; \quad \mathrm{N}=\left[\begin{array}{cc}
0 & -\left[\mathrm{K}_{\mathrm{E}}\right] \\
{\left[\mathrm{M}_{\mathrm{E}}\right]} & 0
\end{array}\right] ; \quad \mathrm{R}=\left[\begin{array}{cc}
{\left[\mathrm{M}_{\mathrm{E}}\right]} & {\left[\mathrm{G}_{\mathrm{E}}\right]} \\
0 & {\left[\mathrm{M}_{\mathrm{E}}\right]}
\end{array}\right]
$$

The condition for nontrivial solutions of Equation (17) is;

$$
\operatorname{det}(\mathrm{N}-\phi \mathrm{R})=0
$$

The eigenvalues of Eq. (20) represent the disturbing frequency $\phi$, that defines the boundaries between stable and unstable region of the rotating shaft under parametric excitations.

\section{RESULTS AND DISCUSSION}

\section{Validation}

A comparison is made between the results of the instability charts of the shaft in this study and those of past researchers [10] that considered at each node, 4 degrees of freedom. Results show that the parametric instability charts correspond to the current work and those of the work of Chen and $\mathrm{Ku}$ [10] are in good agreement as shown in Figure 4.

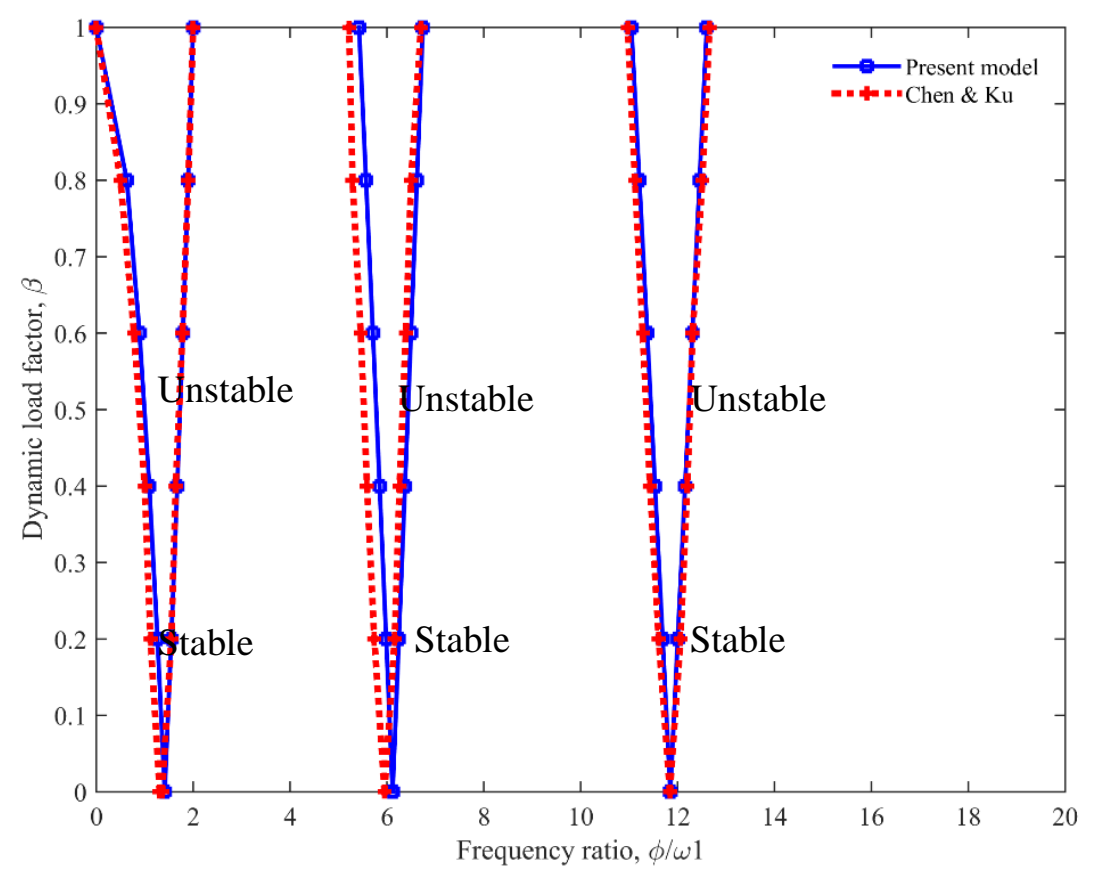

(a) $0 \mathrm{rpm}$ 


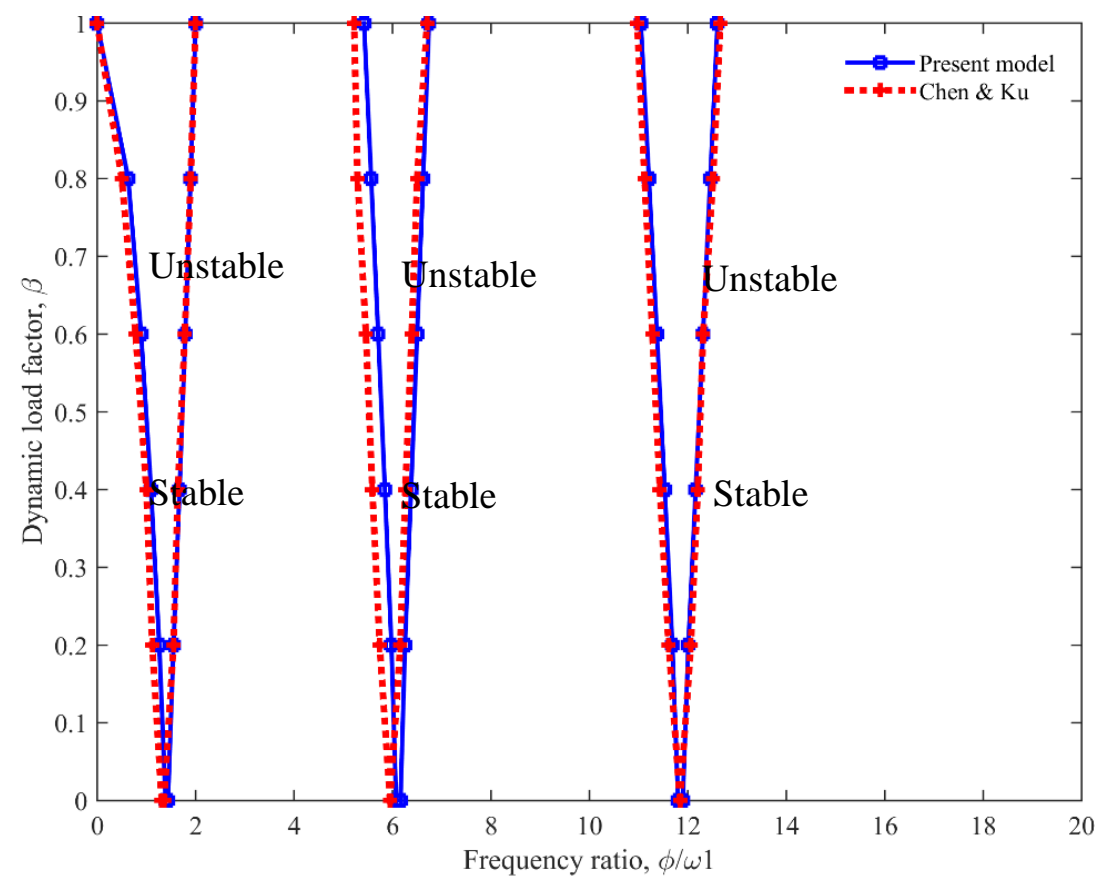

(b) $800 \mathrm{rpm}$

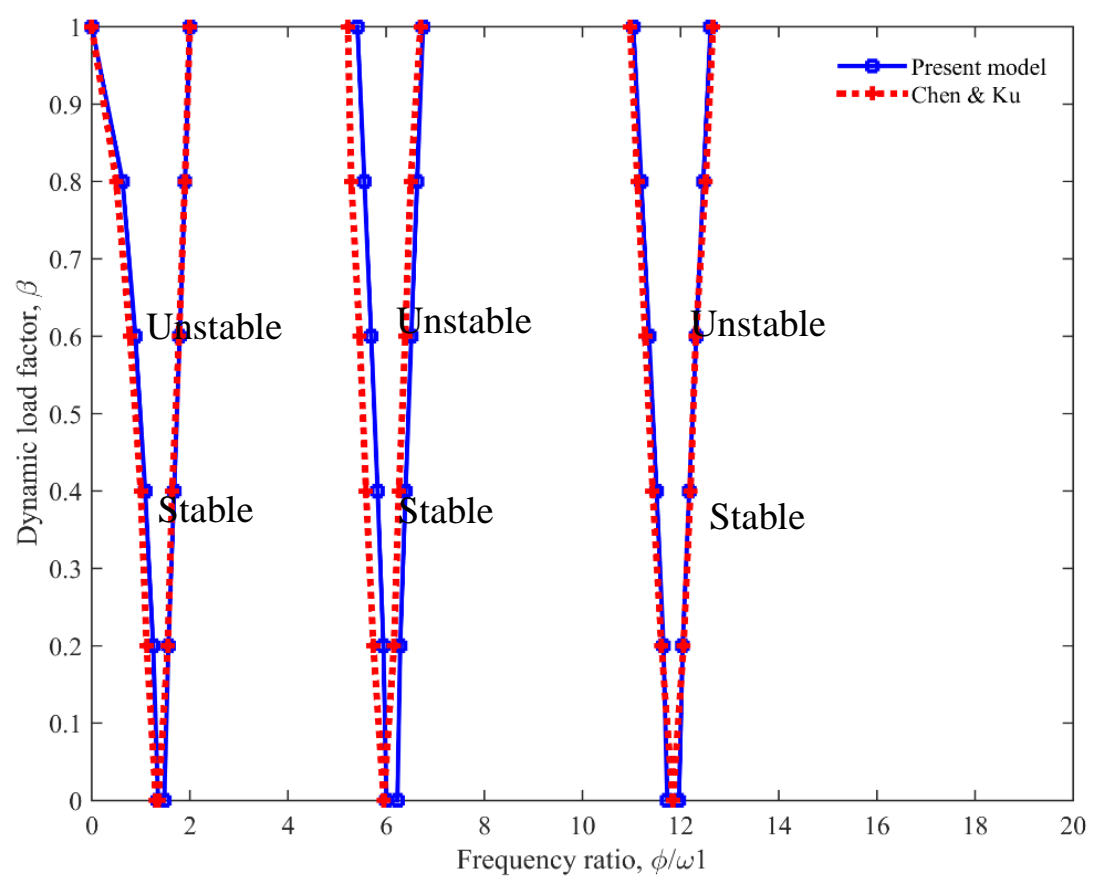

(c) $20000 \mathrm{rpm}$

Figure 4 . The parametric instability charts for the present model and past researchers [10] for shaft rotating at three speeds.

\section{The Effect of Boundary Condition}

In this section, the parametric instability behaviour of the simple rotating shaft system is investigated focussing on the effect of the support condition. Figure 5, 6 and 7 show the instability charts of shafts having dissimilar boundary conditions and rotational speed. Boundary conditions can be seen to significantly affect the instability region as agreed by 
Liew et al. [14]. Figure 5 shows that in a static condition, the instability chart for the fixed-free boundary condition is more stable at a lower frequency compared to the pinpin and the fixed-pin end conditions. Besides, instability regions for both models of 4DOF and 5DOF are quite similar in the case of fixed-pin and pin-pin boundary conditions at the lower frequency. For the fixed-free boundary condition, the instability regions correspond to the 5DOF model is larger than those of the 4DOF model.
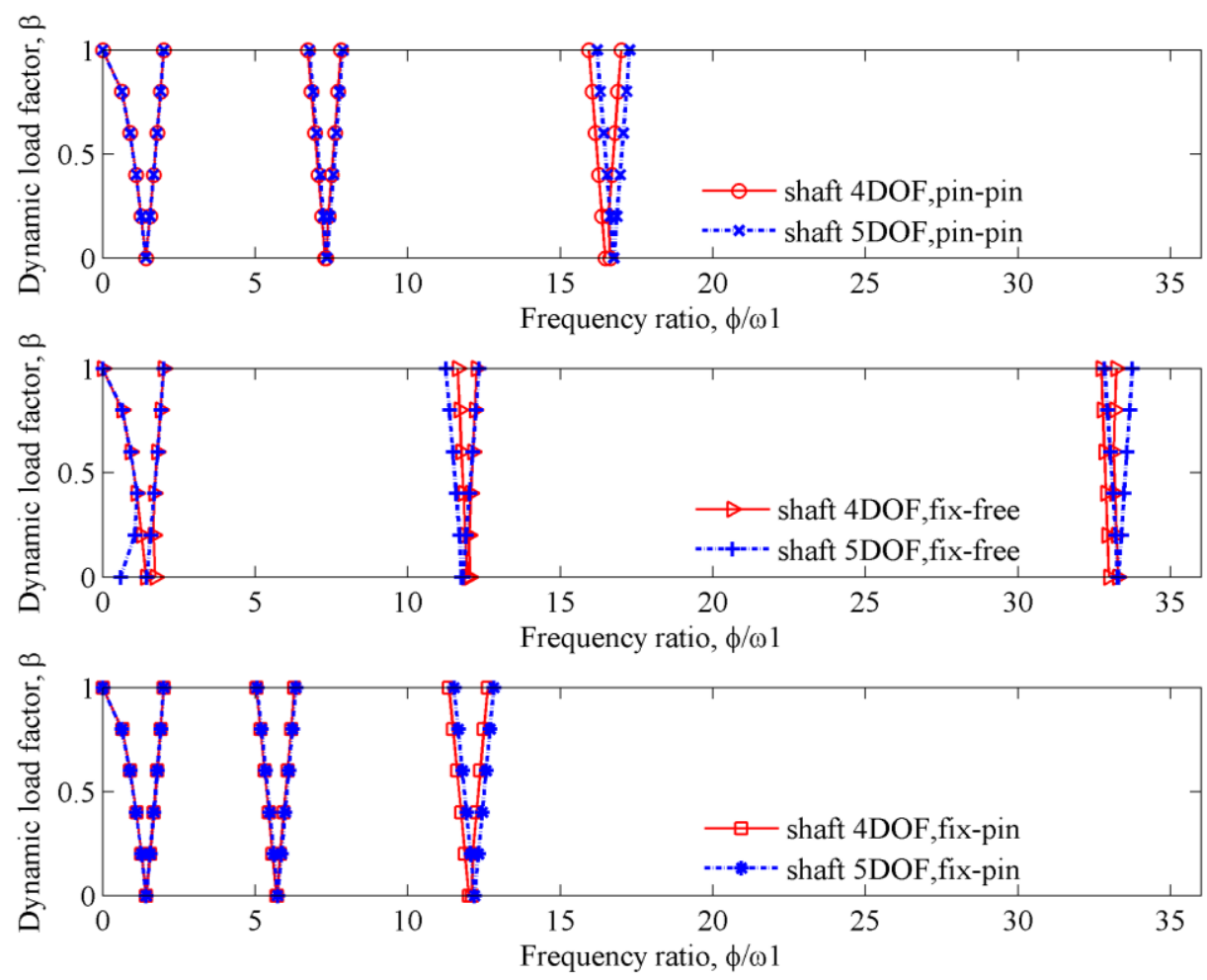

Figure 5. Instability charts of a shaft for different boundary conditions at the shaft speed of $0 \mathrm{rpm}$

Figure 6 and 7 show that the instability region boundaries shifted out and the widths of these instability regions increase as the rotating speed of the shaft is increased. These results are similar to the works of Chen and $\mathrm{Ku}$ [10] and Liew et al. [14]. This phenomenon occurs due to the gyroscopic effect of the shaft that increases proportionally to the rotational speed. Thus, it can be said that the gyroscopic effect has destabilised the rotor system as the speed increases. The effect of torsional deformation can be seen to be significant at the highest shaft speed of 40,000 rpm. At this speed, the parametric instability regions correspond to the 5DOF model that consider the torsional effect differ from the 4DOF models for all cases of boundary conditions. For the $1^{\text {st }}$ mode, due to additional torsional motion element, the instability region of 5DOF has widened compared to $4 \mathrm{DOF}$ model. In reverse, the instability region corresponds to the $4 \mathrm{DOF}$ is wide compared to those of the 5DOF model for the $3^{\text {rd }}$ mode of instability. 


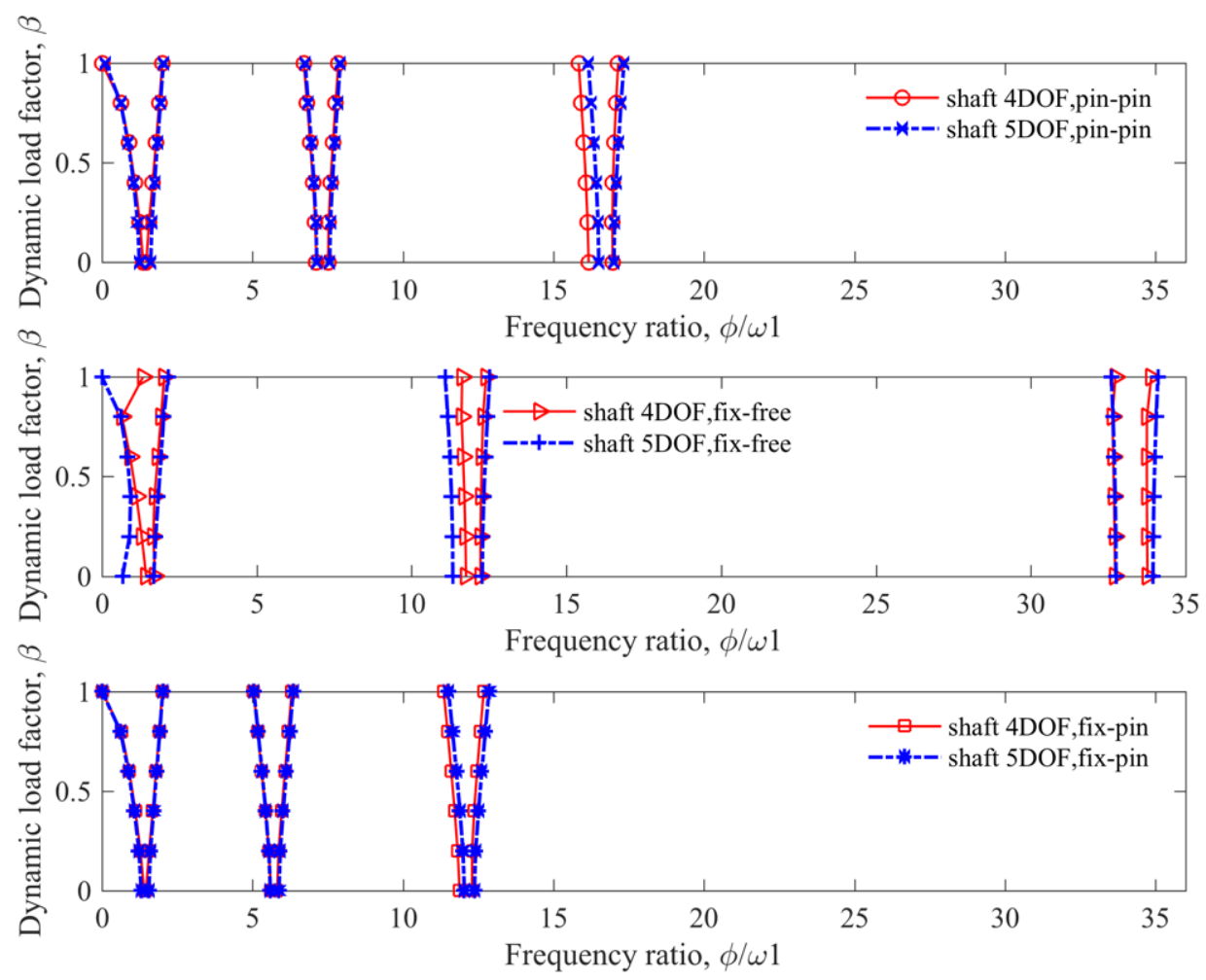

Figure 6. Instability charts of a shaft for different boundary conditions at the shaft speed of $9000 \mathrm{rpm}$.

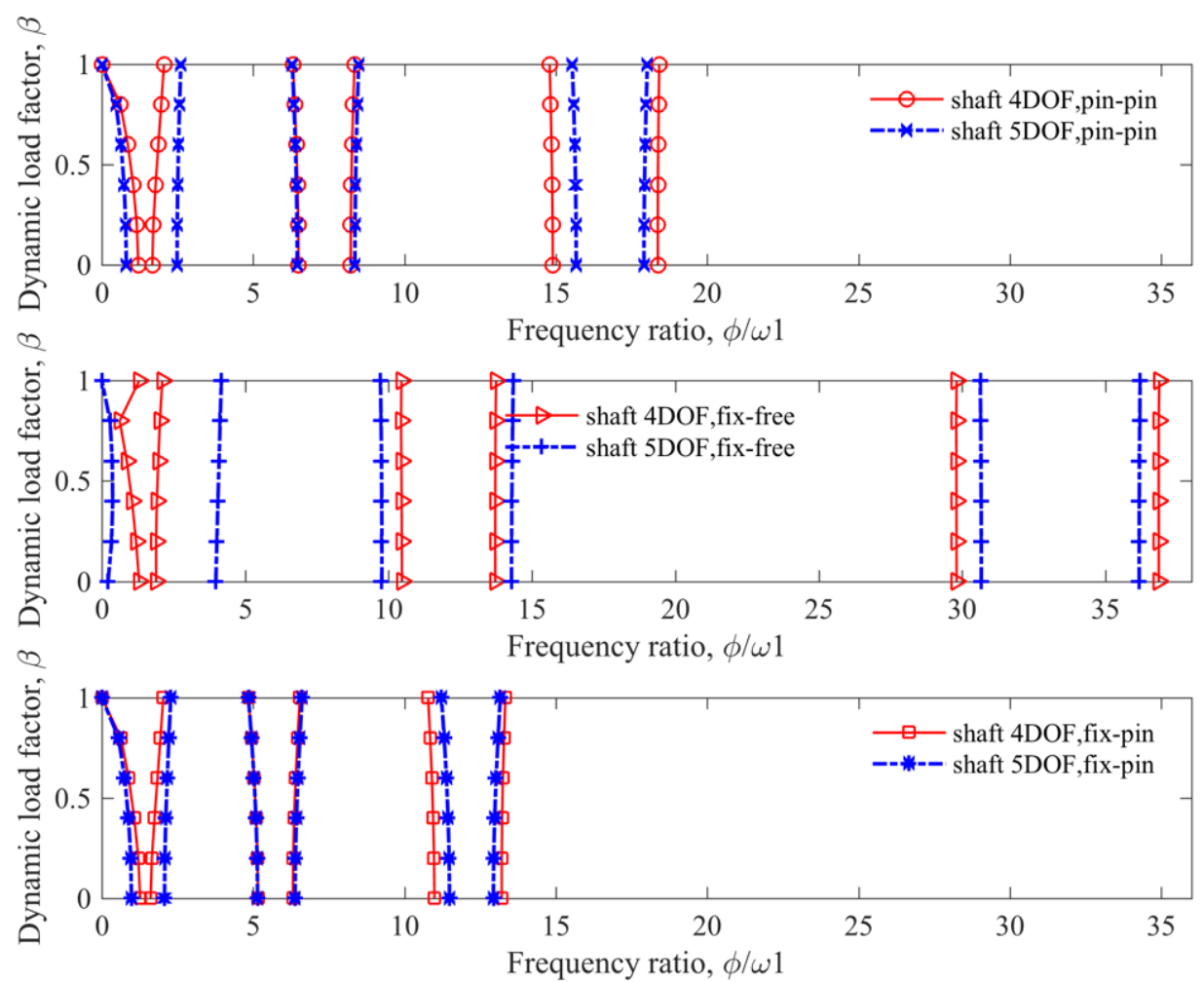

Figure 7. Instability charts of a shaft for different boundary conditions at the shaft speed of $40000 \mathrm{rpm}$. 
Figure 8 shows the difference between upper and lower boundary of instability region between $4 \mathrm{DOF}$ and the $5 \mathrm{DOF}$ models for three cases of boundary conditions. The reading is at $1^{\text {st }}$ modes, and the shaft rotates at $40,000 \mathrm{rpm}$. The three cases of boundary conditions are the pin support at both ends (P-P), the fix or clamp support at one end and free at the other end $(\mathrm{C}-\mathrm{F})$ and the fixed support at one end and pin support at the other end $(\mathrm{C}-\mathrm{P})$. This figure shows that the difference in the frequency ratio of more than $100 \%$ can be seen for the case of C-F boundary condition.

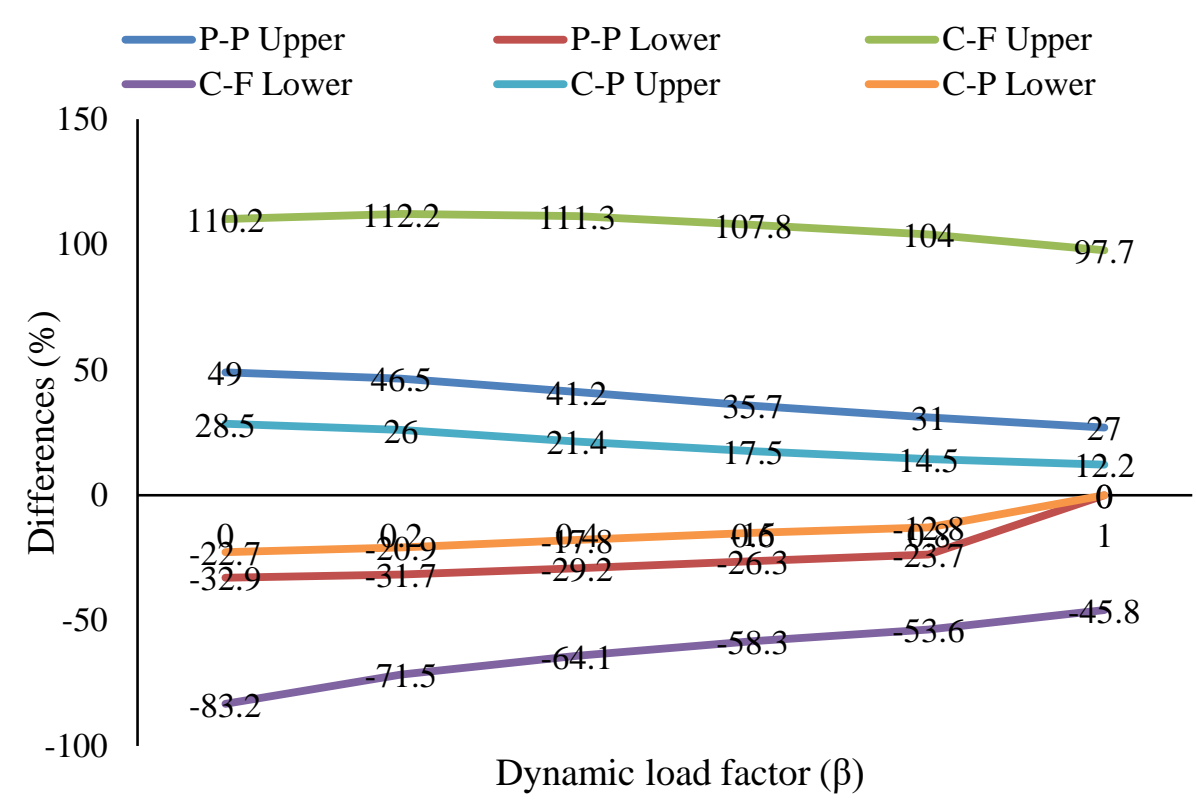

Figure 8 . The comparison of the 1 st mode instability region between the 4DOF and 5DOF model at $40000 \mathrm{rpm}$ for different boundary conditions.

\section{The Effect of Bearing Support}

In this study, bearings are added at both ends of the shaft. The influence of bearing stiffness and the effect of the anisotropic condition of the bearing are considered here.

\section{The effect of bearing stiffness}

The effect of three different levels of bearing stiffness, i.e. the stiff, intermediate, and soft conditions on the instability charts of the shaft is studied. For each level, the bearing is assumed to have equal stiffness in all radial directions besides having no damping element. Figure 9 to 11 show the comparison between the effect of the three levels of bearing stiffness on the parametric instability charts at the shaft speeds of 0,9000 and $40000 \mathrm{rpm}$, respectively. From the observation in Figure 9, the $1^{\text {st }}$ mode instability region of the static shaft does not change as bearing stiffness decreases. However, the $2^{\text {nd }}$ mode of instability region shifted towards zero and overlapped with the $1^{\text {st }}$ mode instability of region as the stiffness level of the bearing decreases from stiff to soft level. The third region of instability, however, is shifted out to the right as the stiffness level is decreased. The shift of the chart to the right is revealed for the case of the soft bearing. 
Furthermore, the instability region also becomes smaller. This condition shows that the shaft system becomes more stable as the stiffness level of bearing move from stiff to soft level. Furthermore, the effect of the torsional deformation is insignificant for a static shaft.
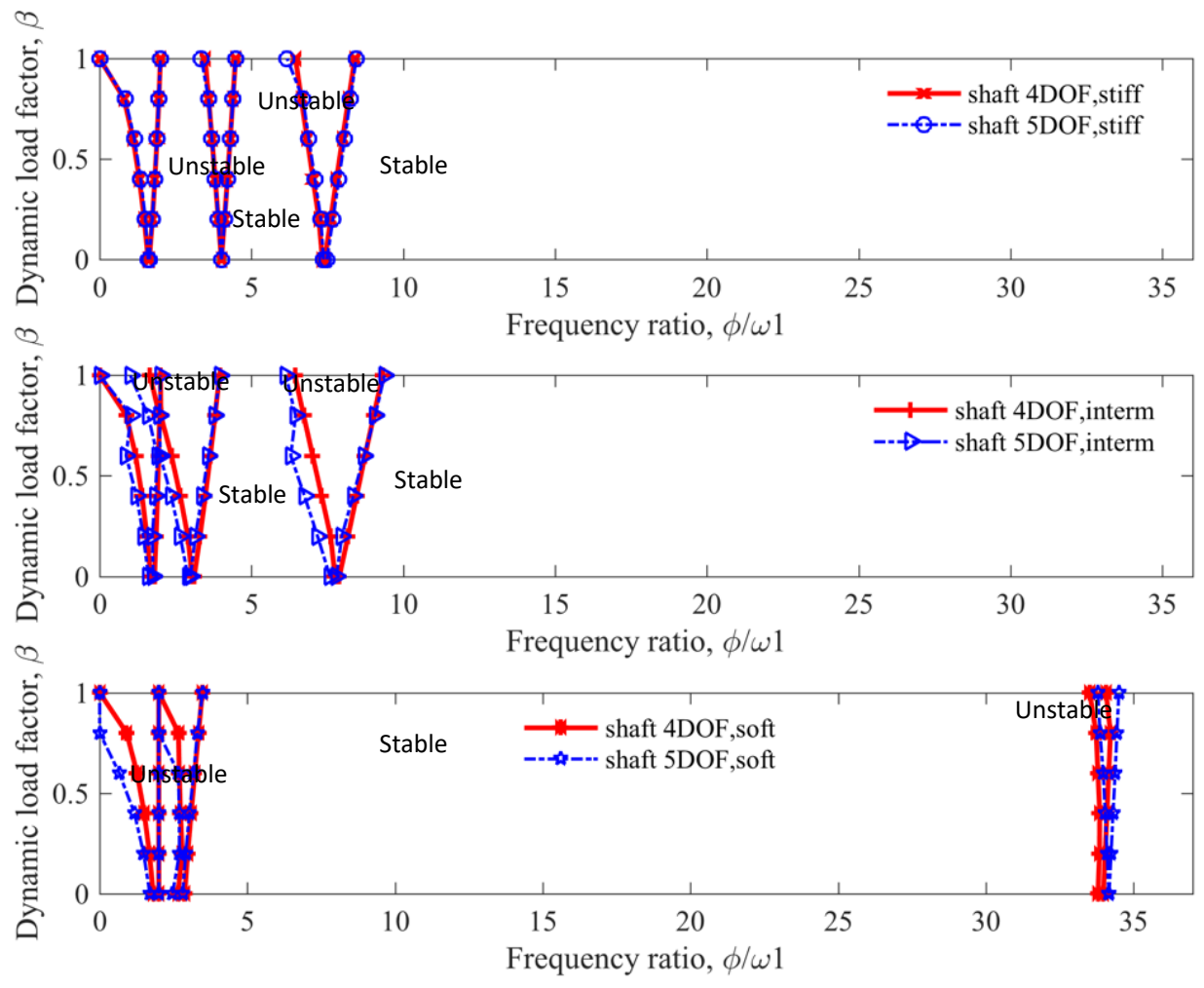

Figure 9. The dynamic instability of shaft at $0 \mathrm{rpm}$ under the influence of bearing stiffness.

Referring to Figure 10 and 11, as the shaft speed is increased, the patterns of the $1^{\text {st }}$ mode remains the same, the $2^{\text {nd }}$ mode shifted to the left and the $3^{\text {rd }}$ mode shifted to the right as the stiffness level of the bearing is decreased in the static shaft can still be seen. However, as the shaft speed increases, the instability region of the shaft increases too. This can be seen for the case the $3^{\text {rd }}$ mode of the soft shaft rotating at $9000 \mathrm{rpm}$ and 40000 $\mathrm{rpm}$. Furthermore, the difference between the instability charts correspond to the 5DOF model and those of the 4DOF model as the shaft speed increases can be visualised especially for the case of soft bearing with the rotating speed at $40000 \mathrm{rpm}$. In this special case, the instability regions of the $1^{\text {st }}$ and $2^{\text {nd }}$ modes for the 4DOF model shifted close to each other while in opposite the instability regions of the $1^{\text {st }}$ and $2^{\text {nd }}$ modes for the 5DOF shifted away from each other. Also, the difference between the width of the instability region corresponds to the $5 \mathrm{DOF}$ and the $4 \mathrm{DOF}$ models can be seen for a shaft with the soft bearing as the rotating speed increases. This proves the significance of the torsional degree of freedom in shaping the parametric instability behaviour of the shaft at high speed. 


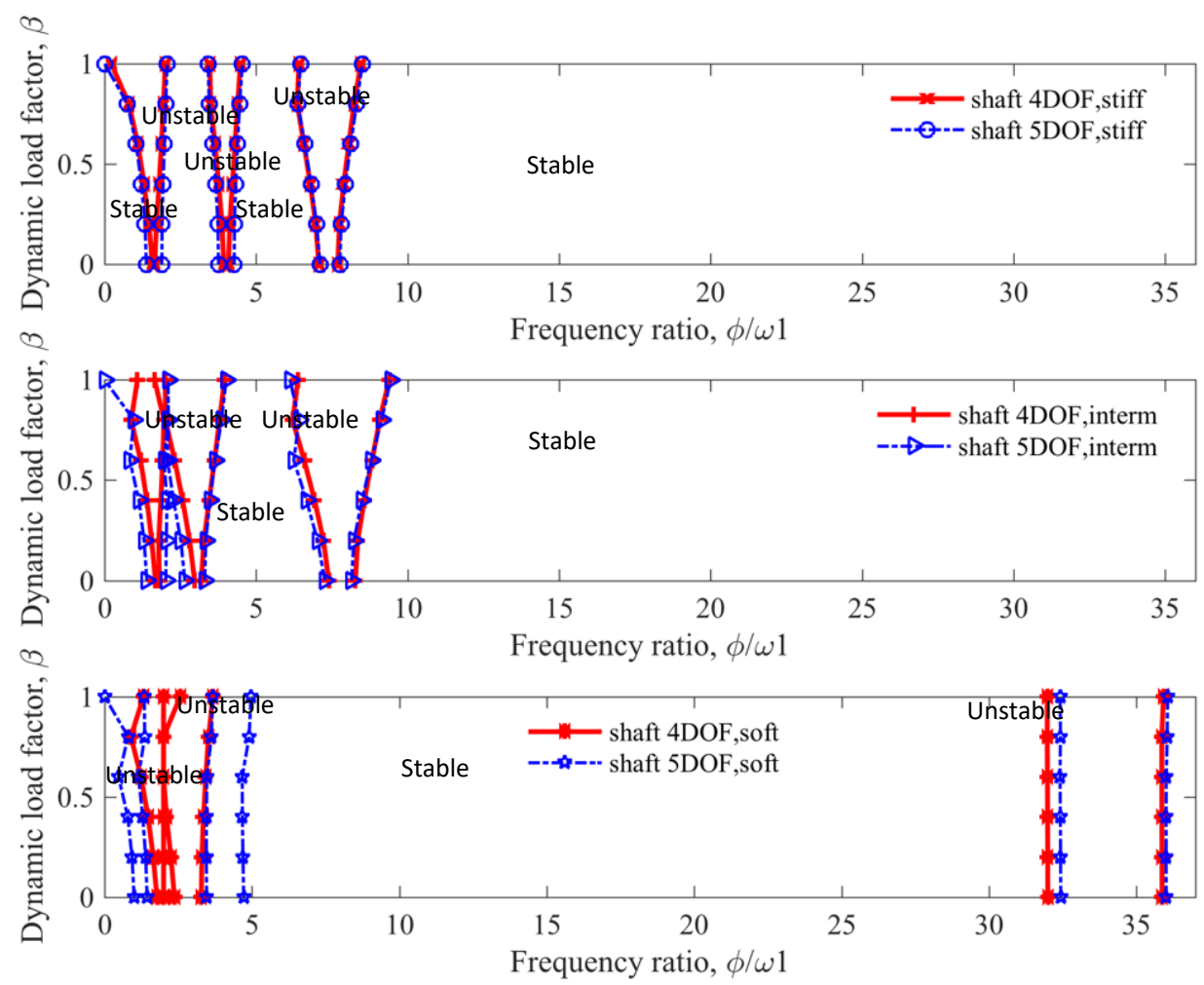

Figure 10. The dynamic instability of a shaft at $9000 \mathrm{rpm}$ under the influence of bearing stiffness.

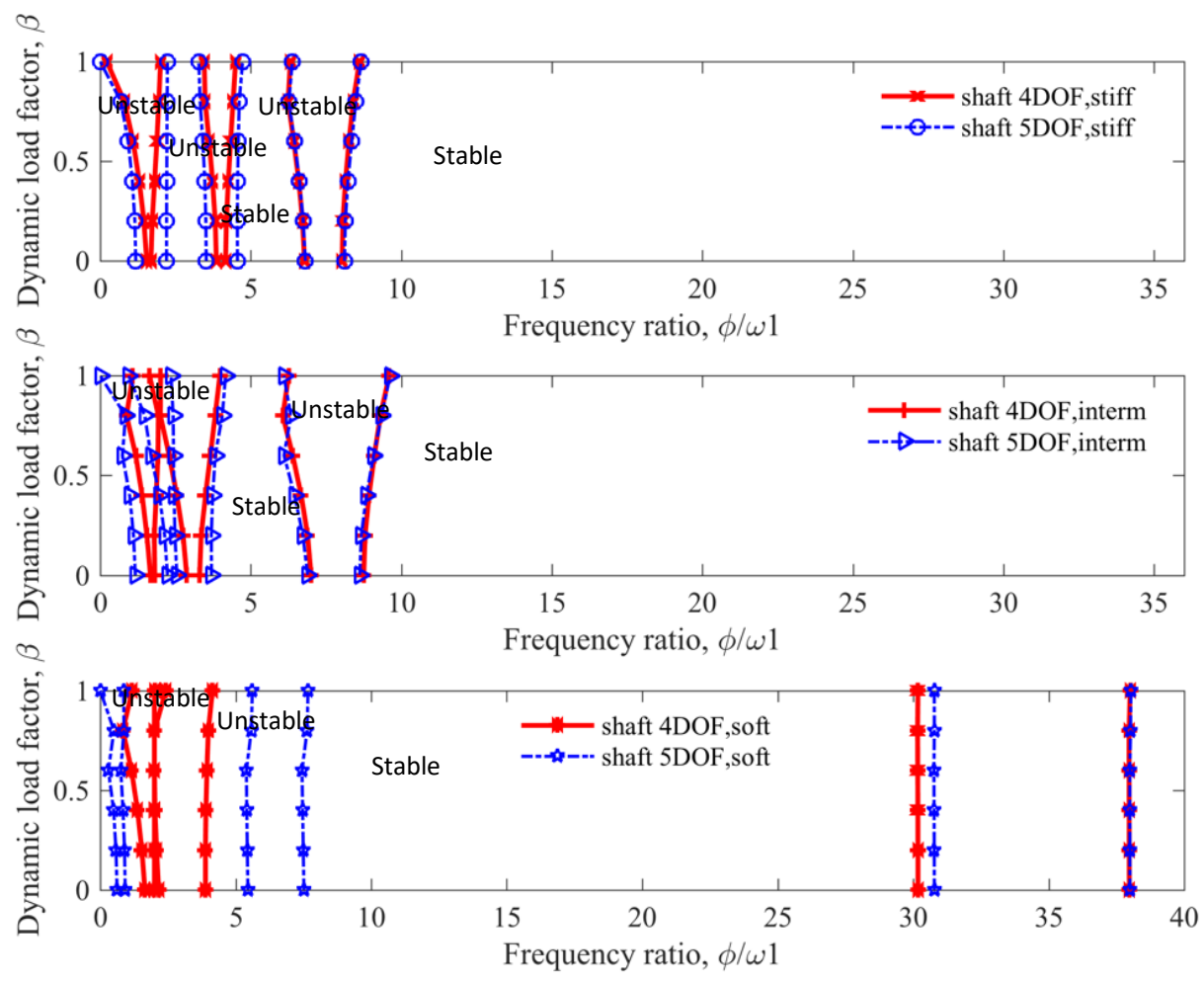

Figure 11. The dynamic instability of a shaft at $40000 \mathrm{rpm}$ under the influence of bearing stiffness. 


\section{The effect of anisotropic bearing}

In this section, the dynamic instability behaviour of the shaft is investigated by changing the anisotropic bearing condition where the comparison is made to that of the rigid bearing. Figure 12 to 14 gives the dynamic instability charts of the rotor system correspond to the 4DOF and 5DOF models for rigid and anisotropic bearing conditions at the speed of 0,9000 and $40000 \mathrm{rpm}$ respectively. In all cases, the instability charts provided by the 5DOF model agrees well with those of the 4DOF except at the speed of $40000 \mathrm{rpm}$. Figure 12 shows that the widths of the $2^{\text {nd }}$ and $3^{\text {rd }}$ modes instability regions correspond to the shaft are somewhat larger than their counterparts in shafts with the rigid bearing. A more significant effect of the anisotropic condition of the bearing is the right shift of the $3^{\text {rd }}$ mode of instability.

Similar patterns of the effect of the anisotropic condition of the bearing can be seen for the shafts at $9000 \mathrm{rpm}$, as can be seen in Figure 13. Figure 14 shows that the 5 DOF model gives the greater widths of instability charts for the $1^{\text {st }}$ and $2^{\text {nd }}$ modes of instability. This shows that the torsional deformation effect is significant for the $1^{\text {st }}$ and $2^{\text {nd }}$ mode of the instability of the high-speed shaft. The effect of high speed may also have caused the non-existence of the instability centre in all modes and for both types of bearing. This is true for results correspond to the 4DOF and 5DOF models.
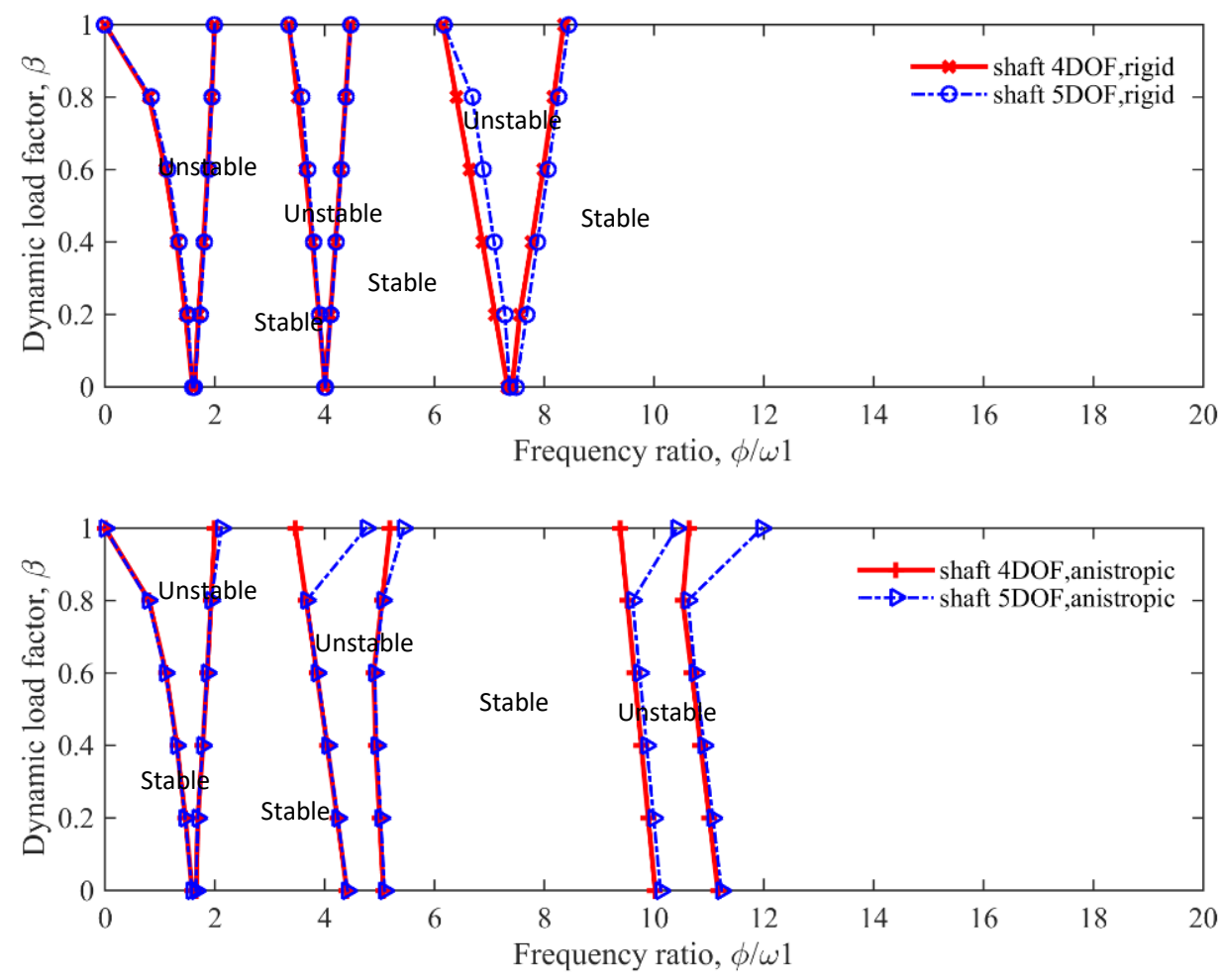

Figure 12. The dynamic instability of a shaft at $0 \mathrm{rpm}$ under the influence of anisotropic bearing. 

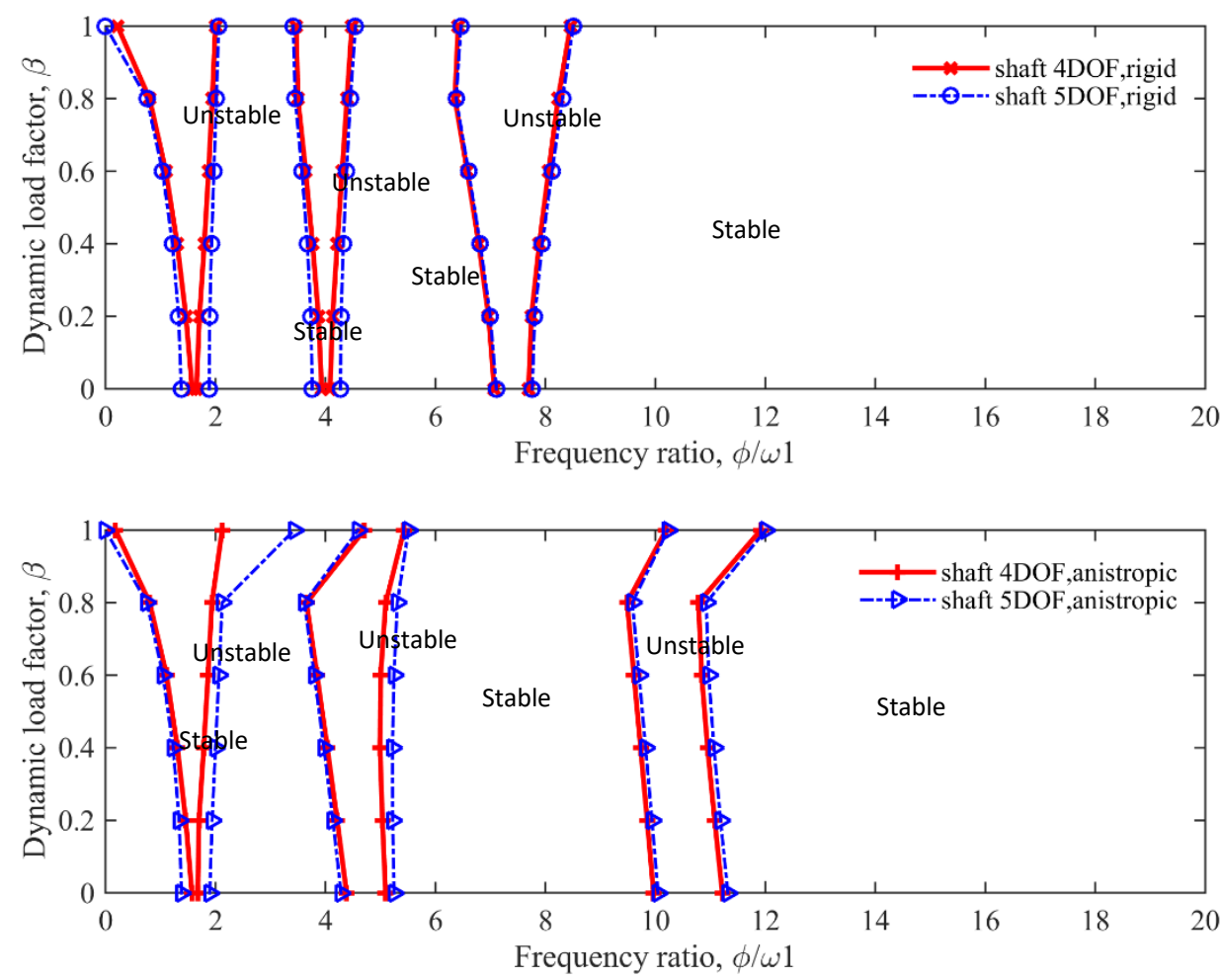

Figure 13. The dynamic instability of a shaft at $9000 \mathrm{rpm}$ under the influence of anisotropic bearing.
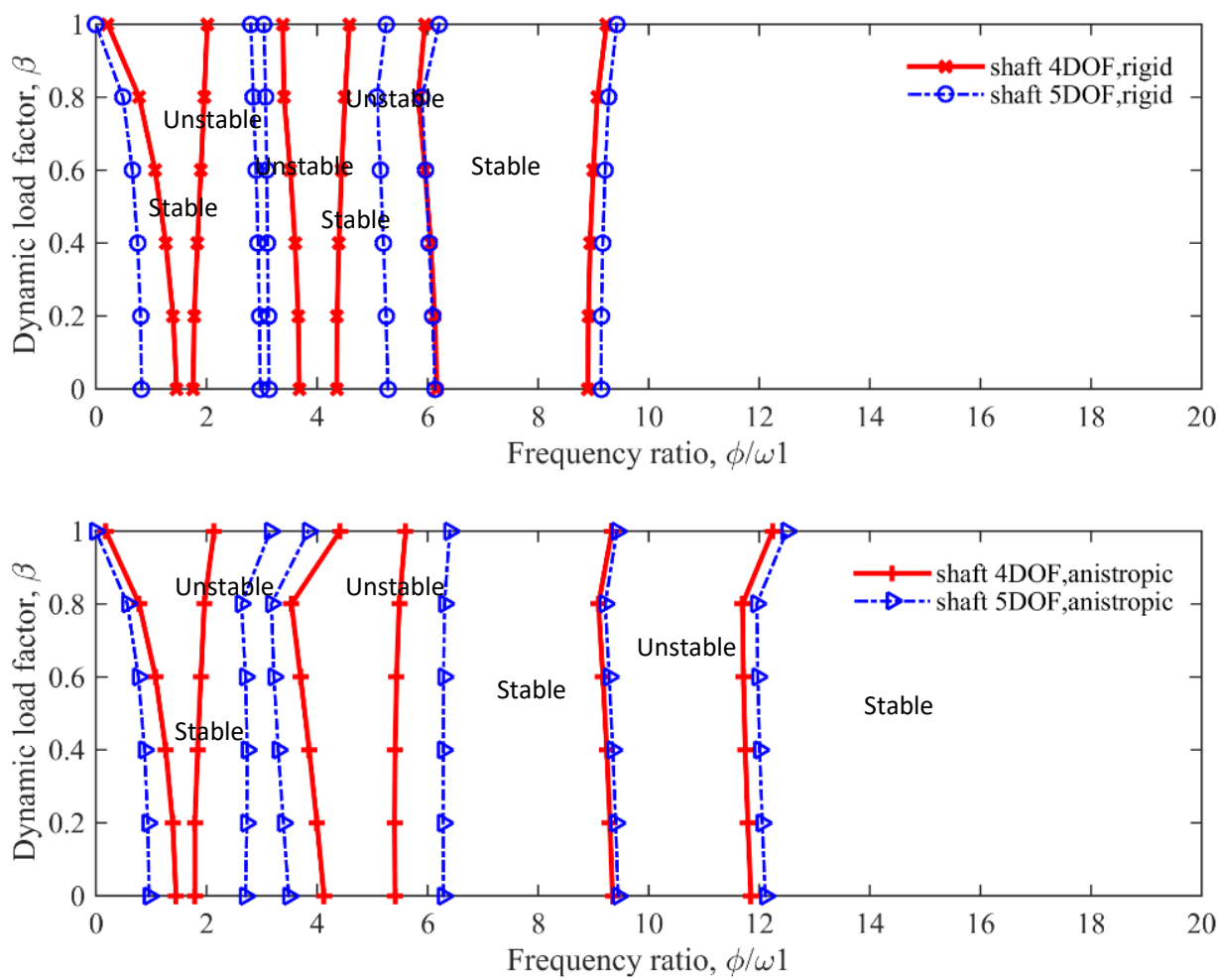

Figure 14. The dynamic instability of a shaft at $40000 \mathrm{rpm}$ under the influence of anisotropic bearing. 


\section{CONCLUSION}

This paper presents the torsional deformation effect on the dynamic instability behaviour of rotor system rotating at high speed. The developed 5DOF model that includes the twisting deformation as one of the degree of freedom gives the needed torsional effect. The rotor system understudied here is a simple shaft system with rigid bearings and a shaft with bearings that differs in stiffness and its anisotropy that are installed at both ends of the shaft. The study shows the significance of the torsional effect that is obvious for shaft rotating at high speed. Furthermore, the increase in rotational speed shift-out the instability chart, thus increasing the instability of the rotor system

\section{ACKNOWLEDGEMENT}

Acknowledgement is gratefully given to the Malaysia-Japan Institute of Technology and Universiti Teknologi Malaysia for supporting the work through the provision of the GUP Grant of Q. K130000.2643.14J90.

\section{REFERENCES}

[1] Darabi M, Ganesan R. Non-linear vibration and dynamic instability of internallythickness-tapered composite plates under parametric excitation. Composite Structures. 2017; 176: 82-104.

[2] Sofiyev AH, Kuruoglu N. Domains of dynamic instability of FGM conical shells under time dependent periodic loads. Composite Structures. 2016; 136: 139-148.

[3] Bakhtiari-Nejad F, Hosseinzadeh A. Nonlinear dynamic stability analysis of the coupled axial-torsional motion of the rotary drilling considering the effect of axial rigid-body dynamics. International Journal of Non-Linear Mechanics. 2017; 88: 8596.

[4] Shahgholi M, Khadem SE. Primary and parametric resonances of asymmetrical rotating shafts with stretching nonlinearity. Mechanism and Machine Theory. 2012; 51: 131-144.

[5] Martynenko G. Resonance mode detuning in rotor systems employing active and passive magnetic. International Journal of Automotive and Mechanical Engineering. 2016; 13: 3293 - 3308.

[6] Mailybaev AA, Spelsberg-Korspeter G. Combined effect of spatially fixed and rotating asymmetries on stability of a rotor. Journal of Sound and Vibration. 2015; 336: 227-239.

[7] Wang S, Wang Y, Zi Y, He Z. A 3D finite element-based model order reduction method for parametric resonance and whirling analysis of anisotropic rotor-bearing systems. Journal of Sound and Vibration. 2015; 359: 116-135.

[8] Han Q, Chu F. The effect of transverse crack upon parametric instability of a rotorbearing system with an asymmetric disk. Communication in Nonlinear Science Numerical Simulation. 2012; 17: 5189-5200.

[9] Chen WR, Chen CS. Effects of locally distributed Kelvin-Voight damping on parametric instability of timoshenko beams. International journal of structural stability and dynamics. 2014; 14: 1-24.

[10] Chen LW, Ku DM. Dynamic stability analysis of a rotating shaft by the finite element method. J. Sound Vibration. 1990; 143: 143-151. 
[11] Ku DM, Chen LW. Dynamic stability of a shaft-disk system with flaws. Computer and Structure 1992; 43: 305-311.

[12] Raffa FA, Vatta F. Dynamic instability of axially loaded shafts in the Mathieu map. Meccanica 2007; 43: 547-553.

[13] Chen PY. Stability boundaries of a spinning rotor with parametrically excited gyroscopic system. European Journal of Mechanics A/Solids 2008; 28: 891-896.

[14] Liew KM, Hu YG, Ng TY, Zhao X. Dynamic stability of rotating cylindrical shells subjected to periodic axial loads. International Journal of Solids and Structures 2006; 43: 7553-7570.

[15] Lin CY, Chen LW. Dynamic stability of spinning pre-twisted sandwich beams with a constrained damping layer subjected to periodic axial loads. Composite and Structures 2005; 70: 275-286.

[16] Ng TY, Lam KY, Reddy JN. Parametric resonance of a rotating cylindrical shell subjected to periodic axial loads. Journal of Sound and Vibration 1998; 214: $513-$ 529.

[17] Yu SD, Cleghorn WL. Dynamic instability analysis of high-speed flexible four-bar Mechanisms. Mechanism and Machine Theory 37 (2002): 1261-1285.

[18] Yim KB, Yim JT. Dynamic stability of a rotor with shear-flexible shaft under axial loads. Journal of Mechanical Science and Technology 2013; 27: 359-366.

[19] Boglietti A, Gerada C, Cavagnino A. High-speed electrical machines and drives. IEEE Transactions on Industrial Electronics 2014; 61: 2943-2945.

[20] Rao JS. Finite Element Methods for Rotor Dynamics. in: History of Rotating Machinery Dynamics SE - 16. Springer Netherlands, 2011, p 269-297.

[21] Nelson HD. A Finite Rotating Shaft Element Using Timoshenko Beam Theory. Journal of Mechanical Design 1980; 102: 793-803.

[22] Bolotin VV. The Dynamic Stability of Elastic Systems. American Journal of Physics 1965; 33: 752.

[23] Tisseur F, Meerbergen K. The quadratic eigenvalue problem. SIAM Rev. 2001; 43: 235-286. 